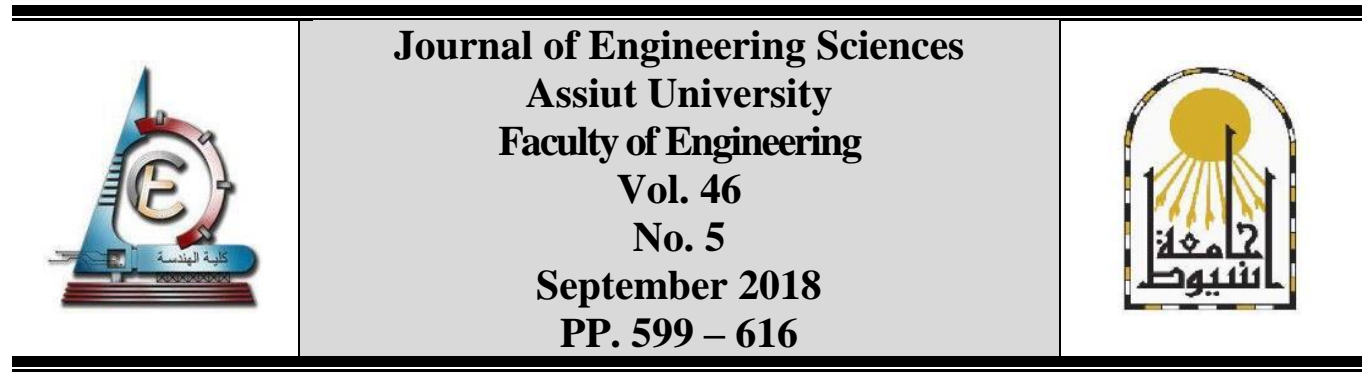

\title{
POST-OCCUPANCY EVALUATION STUDY OF A UNIVERSITY PREMISES IN CAIRO, EGYPT
}

\author{
Sameh M. T. El-Feki ${ }^{1}{ }^{*}$, Mohamed S. Saleh ${ }^{2}$ \\ ${ }^{1}$ Department of Architectural Engineering, October University for Modern Sciences \\ and Arts (MSA) University, $6^{\text {th }}$ October City, Cairo, Egypt \\ ${ }^{2}$ Department of Civil and Architectural Engineering, Sultan Qaboos University, \\ PO.Box 33, Al-Khod, Muscat 123, Oman
}

Received 29 April 2018; Accepted 6 May 2018

\begin{abstract}
This study introduces a post-occupancy evaluation to assess the performance of one of the buildings at MSA University (a pioneer private university) in Cairo, Egypt, from the users' perspective. The main objective of this study is to understand the relationship between the built environment demonstrated in the Faculty of Engineering indoor spaces and the needs of the college community comprising the students and staff. This will underpin the strengths and shortcomings of the present design to facilitate future improvements. The adopted methodology utilizes a number of assessment techniques, including observation, walk-through, questionnaires and interviews. The study culminates with a number of recommended actions to improve the building's performance from the users' (students and staff) perspective, which have a strong impact on the learning experience. These are classified into immediate, intermediate-term and long-term actions.
\end{abstract}

Keywords: post-occupancy evaluation, building performance, indoor spaces, user's satisfaction, higher education buildings, Cairo.

\section{Introduction}

Architectural design is a result of a multi-layered sophisticated process involving various aspects (e.g., philosophical, functional, environmental, aesthetical, contextual, socio-cultural). Yet, the main question is whether or not it succeeded in fulfilling the expectations of the building users: maintaining a good quality of indoor and outdoor spaces; as well as achieving the building's purpose, without neither constraining the indoor environment, nor disrupting work productivity, especially when it comes to educational buildings. Thus, the study believes that one way of keeping the quality of education up to the required standards is to assess and develop the performance of the buildings embracing such activities, via post-occupancy evaluation (POE).

Therefore, this paper studies these aspects employing POE and involving the users' perspective on the subject building (Faculty of Engineering in MSA University) - how they see it, perceive it, and utilize it - in order to improve any shortcomings and to keep the norm of continuous development of the building. This is fostered in terms of 
functionality, building quality, mutual (building/surroundings) contextual influences, and finally the impact of the building on its internal environment including the behavioural aspects of the building's occupants. The findings of this research could be utilized for other buildings in the University or even other Egyptian universities having similar situation.

\subsection{Research objectives}

The main question of this paper is whether or not the design intentions have met the users' expectations. Hence, this research aims at understanding the relationship between the built environment demonstrated in the indoor spaces of the Faculty of Engineering (MSA University) and the needs of the college community represented by students and staff. This aim will be achieved through the users' perspective. The building, which has been fully occupied for more than five years, accommodates more than 1000 students, almost 115 faculty members (full-time and part-time), 80 teaching assistants and 15 technicians [1]. Consequently, problematic areas need to be defined to facilitate building a framework for future enhancements. This should be carried out by conducting a POE study. This main objective is divided into the following sub-objectives:

- To determine the occupants' perception and satisfaction level of their indoor environment.

- To examine the overall performance of the building, with special emphasis on functionality, building quality, and its impact.

- To know if there is a need for specific facilities and/or services that currently don't exist but are required to complement the education process. There is also a need to determine if there are particular spaces that are underutilized and the reasons for that.

- To recommend ways for the improvement of the indoor environment of Faculty of Engineering building.

\subsection{Research methodology}

To fulfil the objectives of this study, a two-phase methodology was adopted. The research starts by laying down a literature review articulating the merits of POE as a means of evaluating, developing and enhancing the built environment. Next, the study sheds light on the types and processes of POE. The first phase ends with a brief explanation about the nature of the required information (qualitative/quantitative) for conducting a POE study. The second phase comprises the case study, the MSA Faculty of Engineering building, including background information about the MSA campus; the employed methods of the case study in which multiple methodologies were implemented; and then findings are discussed; followed by future recommendations and ends with the research conclusion.

The POE investigation (case study) comprised three stages. It starts with exploratory techniques comprising observation of the subject building, interviews with key personnel, and consulting precedent studies. The next stage involves the survey questionnaire, which acts as a focused technique. The last stage is a walkthrough technique representing study verification. These will be discussed in more details later in the 'Case Study' section.

\section{Literature review}

This section introduces Post Occupancy Evaluation, its definition, benefits, drawbacks, types, processes and methodologies. It should be mentioned here that these aspects are introduced in order to facilitate the use of POE as a tool of assessing the subject building, and it is not the intention of the paper to study POE itself. 
Sameh M. T. El-Feki, Mohamed S. Saleh, Post-occupancy evaluation study of a university.......

\subsection{About POE}

Post Occupancy Evaluation (POE) is the evaluation of the performance and function of a building according to users' opinions [2]. POE is an assessment of the efficiency of a designed environment [3]. It is an efficient tool to detect building deficiencies, sustain procedures for facility management, and articulate design and construction criteria. This will consequently help in decreasing the costs of the facility life cycle and make the building more efficient [4].

When assessing a building's performance, there are certain aspects that should be looked into. These comprise the outlook of the building and the statement it makes to the world about the owners and the occupants. These also include activities and spaces that house them, accessibility and circulation, services and amenities, on top of functionality and working environment (temperature, light, sound, etc.). In addition, these involve health and safety, as well as structural considerations and manageability of maintenance and cleaning [5].

\subsection{Types of $P O E$}

POE has three distinct levels:

A. Indicative: Indicative POE covers information about the main strengths and weaknesses of the subject building.

B. Investigative: Investigative POE takes more resources and time to implement as it goes more in-depth. Investigative POE studies the physical performance of a building and users' responses towards it to identify its faults. This is usually carried out utilizing researched and objective criteria that should be clearly expressed.

C. Diagnostic: A diagnostic POE is an in-depth comprehensive examination that requires substantial effort and time. It adopts a multi-layered methodology comprising surveys, questionnaires, physical measurements, observations, etc. Its recommendations involve long-term ones [6], [7].

\subsection{Process of $P O E$}

In order to conduct POE, three consecutive phases need to be implemented:

A. Planning: This phase is essential for setting a plan before evaluation. During this phase, objectives for conducting the POE are identified. In addition, a feasibility study is conducted; backgrounds are attained; an analysis of the building is reviewed to measure its performance; the building's strengths and weaknesses are pinpointed, and its users are identified; resources are listed and planned; schedules are also prepared.

B. Conducting: This process entails three main steps. It starts with data collection, which is a primary task. Information about the building is acquired from users via various methods, e.g., interviews and questionnaires. The second step necessitates a good monitoring and managing system of the data collection phase. The conducting process ends with the data analysis phase in which researchers try to make sense of the data collected.

C. Applying: The main aim of this stage is to recommend actions to be taken to enhance the subject building's performance. To do this, findings are organized and structured according to their priority. Then, actions are recommended. Finally, effects of such actions are assessed to evaluate the success of the POE process [8]. 


\section{Case study}

\subsection{Background}

MSA University is a private university that was founded by Dr. Nawal El Degwi in 1996. It adopted a British education system, and its programs were validated later, either by the University of Greenwich or Middlesex University ${ }^{1}$. Students receive two degrees: a British one and the other are accredited by the Egyptian Supreme Council for Universities [9].

Its original campus was based in Dokki (a few kilometres from downtown Cairo), composed of several villas. Recently, however, the campus has been transferred to 6th of October City, which is about $30 \mathrm{~km}$ from Cairo's centre. The campus has a total area of approximately $210,000 \mathrm{~m} 2$. It includes nine colleges: management sciences, mass communication, arts and design, computer science, engineering, pharmacy, biotechnology, dentistry, and languages. In addition, it houses other services comprising workshops, a library, a cinema, and sports facilities such as gym, football fields, as well as volleyball and basketball courts [9]. The university started a partial move to its new campus in 2005. This move was fully completed in 2008 [1].

The current buildings are occupying only part of the whole plot. There is a ring road that circumscribes the current campus. The buildings are constructed of reinforced concrete skeleton with green curtain walls as an external main feature. The concept is based on a modular unit with a height that does not exceed three floors. The campus started out with four main buildings: the arts and humanities building, the science and technology building, the students' service building and workshop building. Several other buildings were added later including the dentistry and laboratories building, the art and design school, and the gym building. The administration still intends to expand the campus through a multi-phase plan [1].
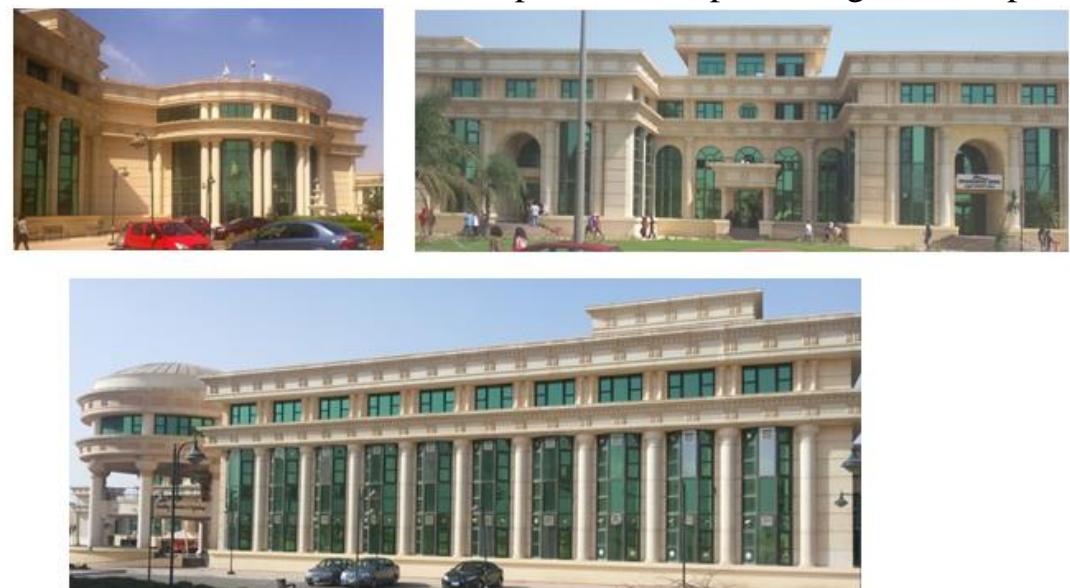

Fig. 1. Different facades of the subject building (Source: Authors).

The Faculty of Engineering was established as early as the founding of the university. It offers four major degree programs: Architecture, Electronics and Communications, Industrial Engineering, and Computer Engineering. The four major degrees were validated by the University of Greenwich, UK, in 2003. The Faculty of Engineering is currently housed in the western building named Science and Technology building. The building's design utilizes an orthogonal grid and houses a number of inner courtyards. It is composed

\footnotetext{
${ }^{1}$ Middlesex University is now replaced by Bedfordshire University.
} 
Sameh M. T. El-Feki, Mohamed S. Saleh, Post-occupancy evaluation study of a university.......

of two floors in addition to the ground floor. The building comprises approximately 10 studios, 8 lecture halls, 35 classrooms, and 45 laboratories (including computer laboratories); it also includes spaces for services, administration and staff rooms. It is realized that the large number of classrooms with a small occupants' capacity is a reflection of the college's policy to optimize educational quality by striking a balance between practical skills, solid theory, and the use of technology [1]. It should be noted that the building also houses a number of Dentistry laboratories and facilities.

\subsection{Employed methods}

Referring to the process of POE, the planning stage started in 2014, then the study was conducted during 2016 and was culminated by the application stage, which was updated late 2017. In regard to the application stage, it is noteworthy that the effects of the proposed recommended actions could always to be assessed. Hence, to evaluate the performance of the building, the research adopted a diagnostic model.

POE is collected through interviews, questionnaires, site visits, and field observations [10]. Having this in mind, the study implemented a methodology that comprises three phases for data collection. As mentioned earlier in the "Research Methodology" section, the first phase is exploratory mechanism, which tends to be more qualitative in nature. This phase calls for the researchers to stand on what works well and what does not in the subject building [11]. This is achieved by utilizing the following techniques: direct observation, open-ended interviews with key persons, and consulting the literature and precedent studies like: [12], [13]. In addition, the research also referred to a number of noteworthy regional studies, e.g., [14], [15], [16].

The second phase is a focused mechanism, which gathers more specific and accurate information [11]. This is done by utilizing a questionnaire survey for the building's occupants (staff and students). In addition, a number of physical measurements were carried out (e.g., building dimensions). This phase also comprised inventories' assessment besides a critical reading into archives and records. Although this phase tends to be more quantitative, it also involves qualitative aspects in different occasions. The third one is a verification mechanism involving a walkthrough evaluation. The main reason for utilizing such a multifaceted methodology with multiple feedback mechanisms is to avoid any shortcomings that may result from using a sole mechanism and thereby obtain more reliable results. The following discussion explains how these mechanisms were implemented in the present study.

\subsubsection{Direct observation}

The researchers' observation is intended to identify the main issues to be thoroughly investigated by using other techniques. In discussing the significance of 'inter-observer reliability', it is claimed that it is built upon comparing observations conducted by different observers for the same scene. This checks if different observers have documented the same single observation/action in the same manner [8]. Hence, the researchers, assisted by two senior teaching assistants, carried out their observations separately and then made comparisons.

The observations were performed by exploring the indoor spaces of the subject building, through repeated tours to document the observed phenomena via written notes, sketches and photographs. These observations were conducted on two different sessions - when the building was fully occupied (during regular terms) and when it was vacant (holidays).

The study capitalized on the work of Zeisel, in that the researchers divided the observed building into two main categories: physical objects and occupants' behaviour. While the 
former involved the consequences of using the object, i.e., if any modifications were introduced to the object to adapt the use and demonstrated messages (self and public). The latter comprised the occupants in each space, their activities, the nature of these activities (individual/groups), the relationship between the actors, and finally, the context within which this activity is performed [17].

\subsubsection{The survey}

The study applied a twofold methodology for the survey. It included qualitative, openended method - one-to-one interviews with key personnel - as a part of the exploratory phase, and a quantitative, structured questionnaire for the students and the staff, to investigate their insights about the performance of the building, in order to address any shortcomings. This questionnaire represents the focused phase.

The observation and the interviews were the main source from which principal issues were defined to be further explored by the questionnaire - i.e., accessibility, provided spaces, existing facilities, environmental and technical aspects, construction and material, contextual issues.

These were conducted on the basis that they represent the perception of the observers and the key personnel, grounded on their experience and thorough understanding of various notions related to the building and its performance, and to what extent it meets their needs.

Hence, the study pinpointed 49 aspects that affect the indoor spaces and the impact of the building to the surrounding context. These were classified under three main umbrellas: building functionality, building quality, and impact of the building. Then, a questionnaire was formulated to evaluate these aspects in the Faculty of Engineering.

- Functionality looks at the way the building is designed. It includes elements relating to building accessibility (signs, room numbers, corridors, lifts, etc.), spaces functionality (reception, studios, classrooms, laboratories, etc.) and building uses (working hours, building management, security systems, etc.).

- Building Quality focuses on the building's technical performance (lighting and daylighting, thermal and acoustical aspects, etc.) and engineering systems (HVAC, plumbing, health and safety, etc.), on top of construction quality and utilized materials (durability, aesthetics, practicality, etc.).

- Impact of the Building concentrates on the surrounding context in terms of form and the use of materials (form appropriateness, materials, colours, textures, etc.) and character and innovation (exterior, interior, character, identity, etc.), in addition to the impact of the building on its internal environment (legibility, control, wayfinding, crowdedness, etc.) and behavioural aspects (privacy, territoriality, etc.).

Obviously, there are some issues that overlap under two main categories. For instance, material as an issue has been tackled twice, one from the building quality perspective and another time from the 'Impact of the building' viewpoint.

The questionnaire involves several techniques based on a scale measuring the degree of appropriateness. It consists of ranking questions that rank different spaces from 1 to 6 (where 1 denotes the highest and 6 denotes the lowest) according to specific criteria (e.g., lighting, acoustics). It also includes yes/no questions. Moreover, it embraces grading questions from 1 to 10 (where 10 is the highest). It also contains a series of short statements measured by 5point Likert scale (where $5=$ strongly agree and $1=$ strongly disagree). Finally, one openended question is introduced at the end of the survey asking for further comments. 
Sameh M. T. El-Feki, Mohamed S. Saleh, Post-occupancy evaluation study of a university.......

Since staff members and students form the major population of the building occupants, therefore the survey followed the stratified sampling technique. Occupants have been classified into user groups and respondents were selected randomly within each group. A total number of 65 questionnaires were distributed to the building occupants. The sample involved 21 staff members and 44 students, most of whom were senior students who spent at least three years in the college. Number of respondents was calculated to achieve a $95 \%$ confidence level with margin of error $\pm 10 \%$. Figure 2 shows the distribution of the survey participants by focus groups.

It is noteworthy to state that the department of architecture has more than half the population of the faculty of engineering. This notion was considered in the sampling and had a direct impact on the findings.

\subsubsection{Walkthrough evaluation}

This step acted as a verification technique for the received responses. This was also intended to cover any issues that were not addressed in the earlier evaluations.

This evaluation was conducted by two teams. Each team was composed of one of the researchers and two senior teaching assistants. The first team's objective was to verify all the outcomes of the previous assessments throughout a pre-prepared checklist, whereas the other team's role was to go through the building to identify any new aspects that were not addressed earlier. Finally, the two researchers conducted a comparison study to make their conclusions.

\subsection{Findings and discussion}

This part highlights the main findings of all data gathering mechanisms and debate interpretations. It is structured with respect to the three main areas, i.e., functionality, building quality, and impact of the building. Table 1 presents a summary of the results, highlighting the level of satisfaction in terms of CABE's Design Quality Indicators (DQI) developed for POE of schools in average score composition [18]. The data show that staff members and students share nearly the same satisfaction level for these design quality indicators.

Interestingly, some of the issues raised throughout the exploratory and focused phases were realized to be resolved when conducting the verification phase, which indicates the presence of a follow-up mechanism to overcome any shortcomings. These issues will be discussed in more details in the 'Recommended Actions' section.

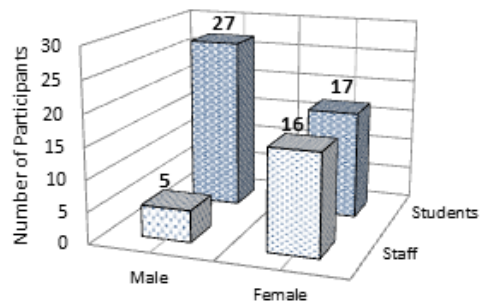

Fig. 2. 3D-Histogram showing number of participants, by focus group (Source: Authors).

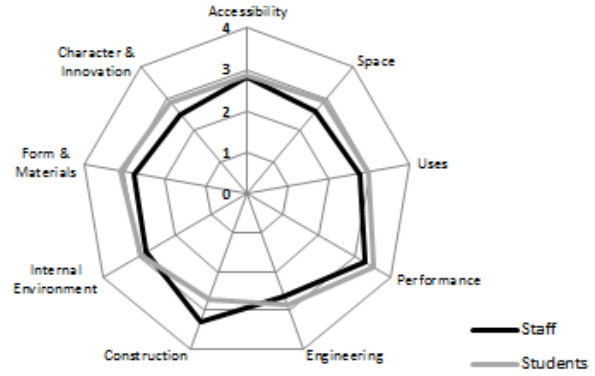

Fig. 3. Radar diagram shows average satisfaction level for user groups with design quality indicators (Source: Authors). 
Table 1.

Survey results showing satisfaction level in terms of CABE's Design Quality Indicators, an average score composition on 5-points Likert scale (Source: Authors).

\begin{tabular}{|c|c|c|c|c|}
\hline & & Staff & Students & Average \\
\hline \multicolumn{5}{|c|}{ Building Functionality } \\
\hline A & Accessibility & 2.833 & 2.852 & 2.843 \\
\hline B & Space Functionality & 2.574 & 2.916 & 2.745 \\
\hline \multirow[t]{2}{*}{$\mathrm{C}$} & Building Uses & 2.775 & 2.996 & 2.886 \\
\hline & Average & 2.727 & 2.922 & 2.824 \\
\hline \multicolumn{5}{|c|}{ Building Quality } \\
\hline A & Technical Performance & 3.308 & 3.529 & 3.419 \\
\hline B & Engineering Quality & 2.619 & 2.841 & 2.730 \\
\hline \multirow[t]{2}{*}{$\mathrm{C}$} & Construction Quality & 3.278 & 2.714 & 2.996 \\
\hline & Average & 3.068 & 3.028 & 3.048 \\
\hline \multicolumn{5}{|c|}{ Impact of the Building } \\
\hline A & Internal Environment & 2.815 & 2.972 & 2.894 \\
\hline B & Form \& Materials & 2.772 & 3.110 & 2.941 \\
\hline \multirow[t]{2}{*}{$\mathrm{C}$} & Character \& Innovation & 2.513 & 2.881 & 2.697 \\
\hline & Average & 2.700 & 2.987 & 2.844 \\
\hline
\end{tabular}

\subsubsection{Functional performance}

Functionality is concerned with the arrangement of spaces and how they are designed to be useful. Occupants were asked to rate their satisfaction of the building performance regarding building accessibility, space functionality, building uses and management. The survey reveals that the mean degree of user's satisfaction regarding building functionality is the least among other building quality indicators with an average score of (2.82).

Building Accessibility

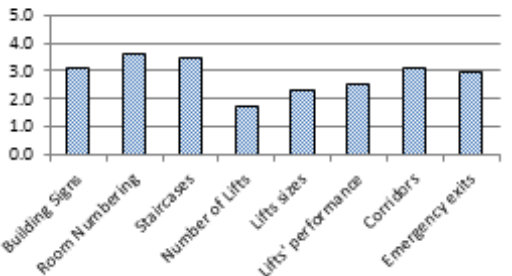

Space Functionality

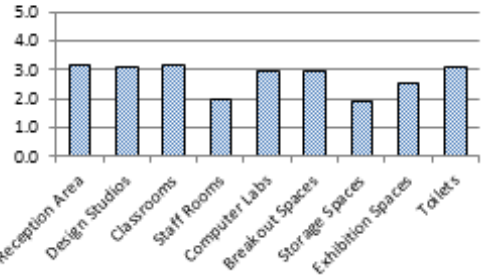

Building Uses

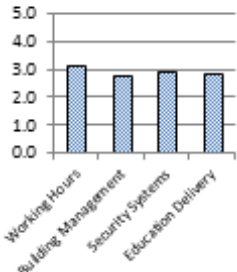

Fig. 4. Average satisfaction score on 5-points Likert scale for the functional performance of the building in terms of building accessibility, space functionality and building uses (Source: Authors).

\subsubsection{Building accessibility}

The issue of building accessibility was clearly realized throughout the observation phase, and was highlighted in the questionnaire responses as a problematic notion. The survey shows that number of lifts is the most disturbing element affecting building accessibility with an average score of (1.74). This suggests that the number of lifts is quite dissatisfying. It is interesting to note that the lifts issue was mostly brought up by students, for that amongst the very few elevators in the building were strictly dedicated to staff and handicapped people. Yet, it could be argued that the need for extra elevators is questionable, as the building comprises only a ground floor and two others. On the other hand, users are more satisfied with staircases having an average score of (3.44). This reflects the adequate number of stairs, their locations, and size, which improve the internal accessibility of floors. The issues of corridors and emergency exits were rated at (3.09) and (2.94) respectively. Although the building has many entrances/exits, most of them are kept closed, which affects the accessibility to the building from different spots of the campus. 


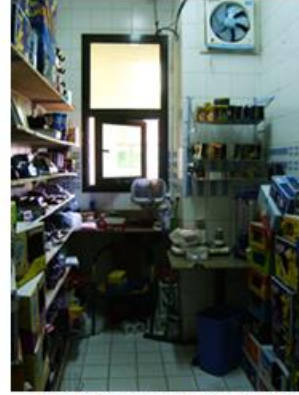

Fig. 5. Very small and crowde kitchenette (Source: Authors).

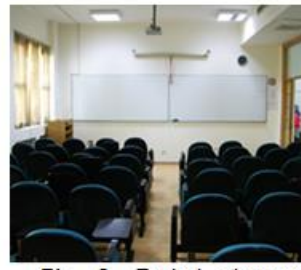

Fig. 8. Typical classroom arrangem ent (Source: Authors).

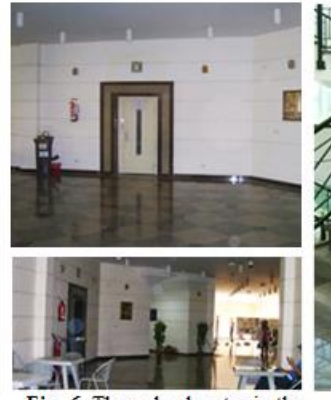

Fig. 6. The only elevator in the Fig. 7. A typical staircase building (above) \& its waiting (Source: Authors). lobby (below) (Source: Authors).

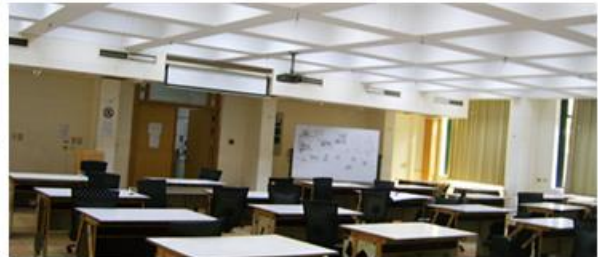

Fig. 9: Typical design studio arrangem ent (Source: Authors).

As for the room numbering and signage, although they were raised in this section, the results showed strong relevance to the issue of way finding, which is discussed later in more detail under the title 'Internal Environment Quality'.

\subsubsection{Space functionality}

Despite the low overall average score of building functionality shown by the questionnaire results in table (1); the observation suggests that spaces are well utilized. Detailed analysis showed that educational spaces such as design studios and classrooms have scored relatively high scores of (3.08) and (3.17) respectively. These spaces were found to be spacious enough to accommodate the assigned number of students, and no congestion is observed; there is a good optimization in this regard, in addition to being well equipped. However, such spaces need to be increased in number because of the growing number of students. As for the computer laboratories, average score of students was (2.96) reflecting the potency of the limited size of these labs and the absence of plotters, up-to-date computers and other advanced equipment. Also, the study shows a clear shortage in faculty office spaces with a score of (1.96). Faculty members have to share their desks, as a result of which a considerable number of them feel less attached to their work and leave the campus immediately after their classes. Moreover, some faculty office spaces are observed to be jammed with desks, preventing smooth movement in these areas.

Results also show a reasonable satisfaction regarding the reception area (the building's main entrance) (scoring an average of 3.17) and respondents positively noted that it was spacious (with double height) and well lit. Additionally, they were fairly pleased about the toilets in terms of being well ventilated and hygienic (with a score average of 3.07).

\subsubsection{Building uses}

In general, the sample shows a moderate satisfaction level of building uses with average score of (2.89). Yet, architectural students noted that they are least satisfied with building management (2.73) as they need to spend more time in the premises due to the different nature of their courses and projects. Unfortunately, and due to security reasons, the campus has to be vacated daily by $4: 00 \mathrm{pm}$ - a factor that is currently affecting the architectural 
studio culture. Hence, students asked for the possibility of expanding their working hours as well as the cafeteria's and provision of vending machines.

On another level, the sample, mostly students, was less satisfied about the building design with average score of (2.81), in that they feel it is not supportive to the delivery of education. On the contrary, the researchers' observations and results of the interviews saw that the building's design well considered this particular aspect.

\subsection{Building quality}

Building quality stems from how well the building is constructed: its structure, fabric, finishes and fittings, engineering systems, the co-ordination of all these factors and how well they perform. The survey shows an overall satisfaction of building quality with an average score of (3.05). Detailed discussion of design quality indicators of building quality are as follows:
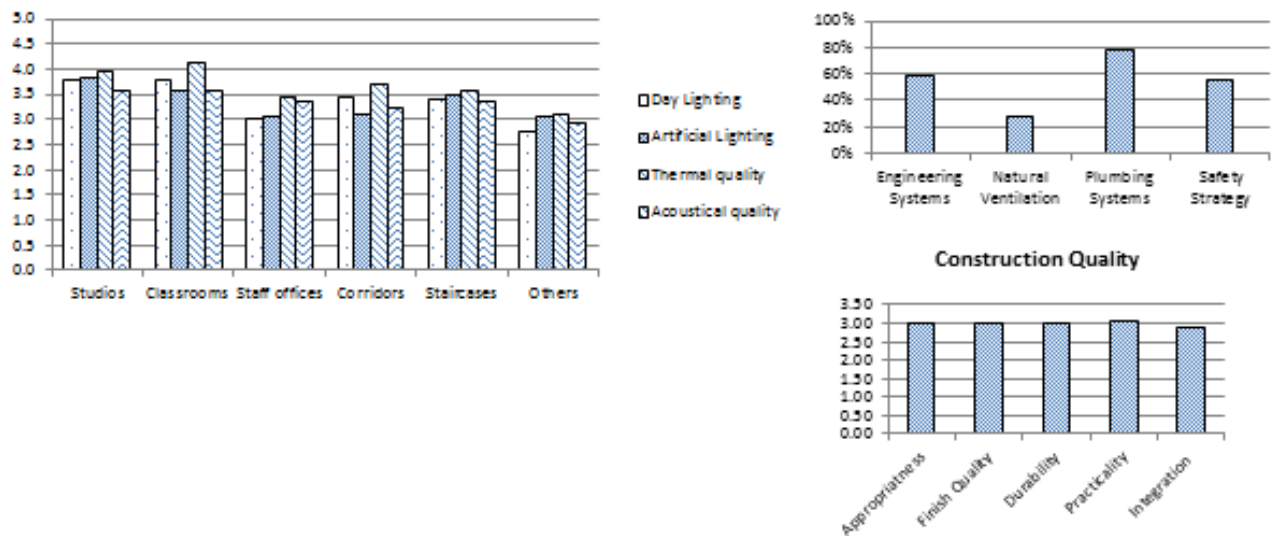

Fig. 10. Average satisfaction score for the building quality in terms of technical performance, engineering quality, and construction quality (Source: Authors).

\subsubsection{Technical performance}

This issue is concerned with the building's lighting, acoustical and thermal systems, in which the majority of the respondents expressed their satisfaction and graded these areas as being within their comfort zone.

As shown in figure (10), thermal quality scored an average degree of satisfaction of (3.65). The following discussion sheds light on the thermal considerations of the subject building to clarify the reasons for this level of satisfaction. The Köppen-Geiger climate classification system classifies the climate of 6th of October City as hot desert where there is largely unbroken sunshine for the whole year due to the stable descending air and high pressure [19]. Accordingly, shading studies had to be well considered. This explains why the authors and their assistants paid special attention to this particular aspect in the walkthrough journeys. It is also because this issue did not have the needed focus and was dealt with as a subset of 'thermal quality' throughout the previous two phases. Hence, when an observer looks at the building externally, it becomes clear that the form of the building achieves this to a good extent. On the other hand, when the observer is distant from the immediate proximity of the building, it becomes noticeable that the designers did not pay the same attention to landscaping, and there is an apparent lack of plants and vegetation around the building. This affects the users around the building and the building itself, because it leaves the structure totally exposed to the severe solar radiation of 6th of 
Sameh M. T. El-Feki, Mohamed S. Saleh, Post-occupancy evaluation study of a university.......

October City climate. As for the indoor spaces, there are two positive observations; first, the internal courtyards are well planted, wherein - in contrast to the building exterior all spaces overlooking these courtyards are less exposed to heat radiation, and consequently, this positively affects the comfort of the space users, knowing that courtyards improve the quality of the morale and work performance of the occupants [20]. Second, one can easily see that a considerable number of lecture halls and studios are oriented with their longer side facing the north, which is a preferred orientation because it allows the daylight in without exposing the occupants to the glare and discomfort of direct sunlight and its consequent heat transmission, and as such no shading devices are required; furthermore, this orientation also takes advantage of the prevailing wind direction. In other spaces that don't have the same orientation, the occupants don't have an equal level of thermal comfort, especially near windows due to the direct outside heat transmitted into the building. Although the windows have internal shading treatment, in an attempt to compensate for the absence of appropriate external shading devices, it proved to be not enough. As a result, this heat transmission requires a huge amount of energy from the HVAC systems to overcome the heat (this is more elaborated in 'Engineering Quality').

As for the natural and artificial lighting, the respondents showed a moderate level of satisfaction, wherein the achieved average level is (3.36), (3.34) respectively. The sample was generally happy with both types and they thought they were good in the educational spaces scoring an overall average of (3.73). While other spaces (e.g. lobbies, a number of admin rooms, etc.) scored a lower average of (2.90), which was exemplified by one of the respondents with the following statement: 'The lobbies preceding the toilets are not very well lit'.

Finally, in regard to the acoustical aspects, it recorded an overall average of (3.33). Generally, most of the respondents were content with the educational facilities (studios, classrooms, etc.) acoustics and commended on it having an average of (3.57).

\subsubsection{Engineering quality}

This section looks at the building's electro-mechanical and safety systems. To start with, the design of the building is based on internal courtyards, which gives a better energy performance in hot climates (both dry and humid) [20]; nevertheless most of the windows were observed to be closed all the time, which limits air movement as well as the quality of indoor natural ventilation. This explains why respondents show their satisfaction level of natural ventilation by only $(26.89 \%)$. Yet, it is the researchers' observation that this is due to the mismanagement of the building, and not because of the building's design as it is well designed in that specific regards. Furthermore, it was realized that the whole building is equipped with central air conditioning systems that are working all the time. Consequently, the amount of energy consumption needed for the air conditioning systems is very high as mentioned earlier.

On a more positive note, most of the respondents think that the building's plumbing system is efficient, with a satisfaction level of (77.65\%). It is working properly and is well maintained, the thing that is reflected positively on the health and hygiene aspects. Less satisfaction level of (54.60\%) was shown towards the safety strategy, despite the fact that there is a firefighting system within the building. This could be referred to the fact that a considerable number of respondents were not aware of the existence of the firefighting system, others thought it is not functioning. 


\subsubsection{Construction quality}

This section is concerned with how well the building is put together. The structure of the building depends on concrete columns and slabs. The windows are made of green glass panels supported by aluminium frames. The entry doors are made of aluminium sections, while the main entrance is composed of a curtain wall that spans over a double-height entrance lobby.

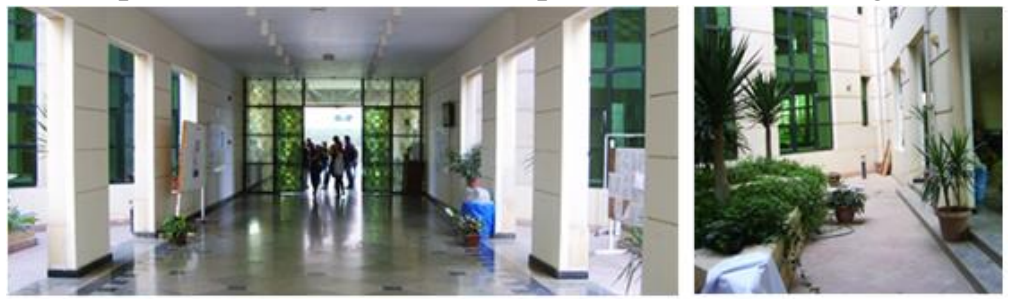

Fig. 11. Panoramic views for the promenade leading to secondary entrance with courtyards on both sides (Source: Authors).

Based on the occupants' survey and site observations, it can be concluded that the building as well as its fixtures and fittings are regarded as durable and well maintained, with an average degree of satisfaction of (3.02). As for the internal finishing materials (floorings, walls and ceilings), a reasonable percentage of the respondents expressed a good level of satisfaction towards their overall look, appropriateness, and practicality, scoring an average of (3.00), (3.03) and (3.04) respectively. However, when it came to the integration of fittings and finishes, the occupants demonstrated a little bit less contentment, having an average level of (2.89).

\subsection{Impact of the building}

In general, this includes the building's ability to delight, to create a sense of place, and to uplift the local community and environment. Thus, and as mentioned earlier, it mainly entails a twofold study. It starts by focusing on the building's impact on its internal environment. Then, the study examines the impact of the building on the surrounding context. The survey discloses that respondents are moderately satisfied with internal environment quality, as well as form and materials of the building with an average score of (2.89) and (2.94) respectively. On the other hand, the study shows that users are less satisfied with the architectural character scoring only (2.70).
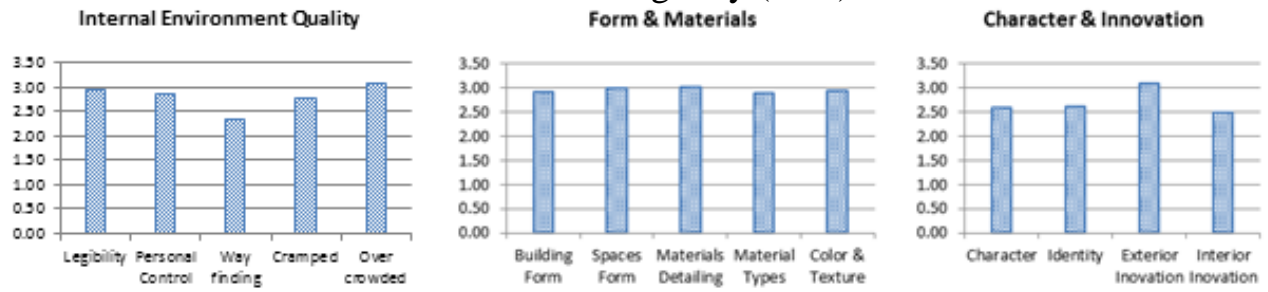

Fig. 12. Average satisfaction score for the impact of the building in terms of internal environment quality; form\& materials; and character \& innovation (Source: Authors).

\subsubsection{Internal environment quality}

It is worth noting here, and as discussed earlier under 'Space Functionality', that an equal territorial notion affects staff members, where they have to share the same workspaces, which leads to feelings of discomfort or dissatisfaction, and hence, be a bit detached from the school, This is reflected from the achieved score of being over crowded (3.08), in addition to being discreetly cramped (2.79). 
Sameh M. T. El-Feki, Mohamed S. Saleh, Post-occupancy evaluation study of a university.......

Along the same lines, there are comments regarding circulation and the way finding of spaces with an average satisfaction score of only (2.34). It is known that way finding is, to a certain extent, based on signage system, sign designs and their legibility are very important factors that affect the way finding system, in addition to room numbering. Those two aspects were mentioned earlier under the sub-title 'A-1 Building Accessibility'. Building signs scored an average of (3.09), while room numbering system recorded (3.62). Yet, almost half of the study sample stated that they face difficulty and feel lost when moving inside the building, to an extent that sometimes they have trouble orienting themselves within the building and in relation to their destinations. Students who have experienced such difficulties illustrated their confusion with comments such as 'all corridors look similar'; 'although the number of signs are reasonably good throughout the building, but they need to be increased in number and better distributed' and 'signs are not clear enough, they may need to be redesigned'. These quotes clarify the conflict between being satisfied of the signs and room numbering system from one side and facing difficulty in reaching destinations within the building from the other side.

Generally, respondents were reasonably satisfied regarding the legibility and personal control of different spaces in the building with an average score of (2.98) and (2.89) respectively.

One last point, the privacy of students and the shortage of private individual workspace is a common and well-observed complaint. It is a common practice in schools of architecture that students have their own spaces, where they can work, and safely leave their work without being touched or looked at by other people. In fact, the majority of architecture students have raised this issue, asking for their own private workspaces as well as lockers to securely leave their stuff in. This is despite the fact that they were not explicitly asked about it. Apparently, this could be a discouraging factor and a source of discontentment for students, as they don't have their basic needs fulfilled, and this could consequently affect their performance.

\subsubsection{Form and materials}

The building has a regular form that depends on a hierarchy of courtyards to form the way it looks. Materials used for external finishes are typical paint on plaster in addition to green-tinted curtain walls. In average respondents reported that they consider the building's form and shape appropriate to its use and environment, and that the form of different inner spaces is reasonably pleasing with an average satisfaction score of (2.94).

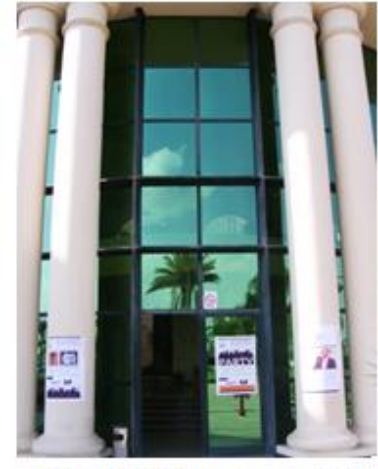

Fig. 13. Main entrance of th (Source: Authors).

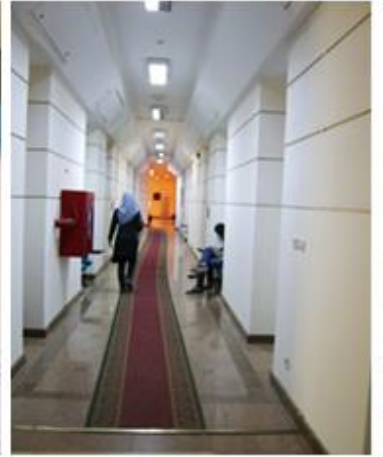

Fig. 14. Typical corridor inside the building showing absence of the groundfloor(Source: Authors). identity \& architectural character (Source: Authors).

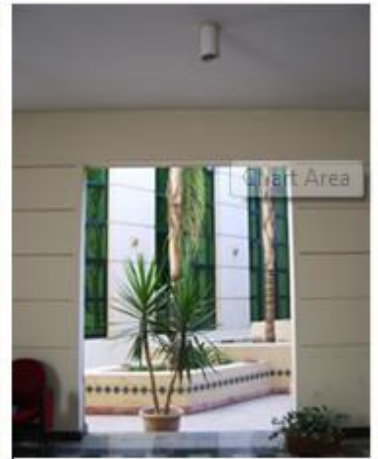

Fig. 15. One of the courtyards in 
Furthermore, many of the participants believed that materials of the building's envelope are well detailed and employed. However, when it came to the inner spaces, rather unexpectedly, the staff were not as pleased (with a satisfaction score of 2.68) and expressed their feeling that such materials, colours and textures do not add to the quality of spaces that much and are considered not interesting. One of the staff noted that it needs more colours and vibrancy'. On the contrary, students were more pleased about both the colour and texture (with a satisfaction score of 3.11) and considered them really appropriate to the college.

\subsubsection{Character and innovation}

The study revealed several problematic issues regarding the building's image with an average satisfaction score of only (2.70). Architectural character and identity were among the least qualities to be satisfied by users with an average score of (2.60). Interestingly, these came mostly from the responses of architecture students - a considerable portion of their responses were in agreement that the architectural department is not distinguishable through the current image of the building and does not have an identity of its own. Furthermore, a number of students explicitly mentioned that 'All buildings look alike' and 'We cannot identify it except when reading the department's sign'. On another hand, almost half of the sample finds that the neo-classic style of the building is appropriate for higher educational buildings in general and the Faculty of Engineering, including the Department of Architecture in particular, especially with the green colour and design that integrates well with the landscape. Meanwhile, minority of the sample showed their interest in a new contemporary design that reflects architectural spirit.

The questionnaire further shows that the respondents were happier about the attractiveness and innovation of the building's exterior more than its interior with an average satisfaction score (3.09) and (2.49) respectively. This was clarified by a number of them stating that the interior looks very traditional and classic, whereas the exterior with its green curtain wall gave a special innovative look to the building.

\subsection{Recommended actions}

The study illustrates that the building has several positive aspects as well as a number of shortcomings. Accordingly, and to improve such shortcomings, maintain the role of the building and enhance its performance, the study presents a set of recommended actions. These are classified into immediate, intermediate-term and long-term actions.

Fortunately enough, and because of the university's commitment to maintain and enhance quality, it was realized that some of the raised problems were resolved during the process of conducting this research. These are as follows:

- Building accessibility: It was clearly observed that all entrances and exits are functioning and serving, and were not kept closed any more.

- Space functionality: Two rooms were given to the architectural department staff, one to the faculty and the other to the teaching assistants. Hence, staff members no longer have to share desks, although they still shared the space. Furthermore, the complaint about the space being jammed with desks has been alleviated after additional space was given, and the flow of movement is now smoother within the space. In addition, the department of architecture was granted two storage spaces one on the rooftop and the other within the department. However, neither space is wide enough to accommodate the exhibit stands. These will be located in other 
Sameh M. T. El-Feki, Mohamed S. Saleh, Post-occupancy evaluation study of a university.......

larger storage areas as promised by the university. Finally, the university managed to prepare an exhibit space; although it is not large, the extra space helps.

- Building uses: limited allowance to stay on campus till 5:00 pm was granted. Yet, it is still not enough.

As for the remaining issues, and in the view of the above findings, the following list of recommendations needs to be addressed in the future.

\subsubsection{Immediate actions}

Although partially resolved by having some of the architectural students' projects hung up in the corridors of the architectural department, it is not enough to entirely resolve neither the identity nor the way finding issues. It is highly recommended that a new plan for signage system be adopted to distinguish between different departments within the building. This plan may include adding new signs, sign design, sign legibility, and sign distribution throughout different areas. It is also suggested to make strong variations in colours through corridors, add more 'you are here' maps, put signs for names of departments and main spaces (e.g., dean's office, head of department), and not only by room number.

Building management should utilize natural ventilation and make better use of the available courtyards, basically by opening windows in public non-educational spaces to allow for cross-ventilation.

Building management should immediately assign a budget to purchase all the required equipment and facilities (e.g., design studio chairs, plotters, 3D plotters, laser cutters, upto-date servers, vending machines).

\subsubsection{Intermediate-term actions}

To reduce energy consumption, the administration needs to develop an optimization strategy for the air conditioning system (i.e., not to have them turned on all the time).

Education campaigns can be organized to foster consciousness about the high consumption of electrical power and to promote a sustainable culture amongst the university's community. In addition, awareness should be disseminated about different safety precautions, particularly fire emergency procedures, and periodic fire drills should be conducted, so that the whole community becomes aware of all the safety measures taken by the university.

\subsubsection{Long-term actions}

In order to enhance the educational environment, it is required to conduct a thorough spatial study of the building comprising space inventory, utilization and reallocation to stand on possibilities of accommodating all required area increases in already existing spaces (faculty office space, computer laboratories) as well as adding new spaces to house the newly required functions (departments' libraries; plotting, printing and copying centre; faculty lounge). This reallocation should include moving all dentistry facilities to the new dentistry building, and considering the cost of such a move; this may be implemented on a longer term basis. It should be noted here that it is better to locate 3D plotters and laser cutters in the workshop building.

The spatial study should also look into the possibility of providing private workspaces for individual students within the design studio, allowing a limited interaction to permit collaboration when needed. This will have a positive impact on the level of satisfaction of the occupants and their attachment to the college, and will consequently contribute to the improvement of the architectural studio culture. 
Another issue that will also help in developing architectural studio culture is to keep an eye on the security status, and when things become more stable, students would be allowed to stay on campus for longer durations and extend the working hours for cafeterias and other services.

The administration also needs to conduct a study to introduce external shading devices to building facades, in coordination with the rest of the campus, which may be carried out on a longer term basis. Meanwhile, it is also necessary to immediately revisit the issue of internal shading devices and ensure that they are all functioning properly. This will contribute to the enhancement of occupants' thermal comfort within such areas.

There is a need to develop a facade study that could be based on distinguishing different buildings according to their functions and the occupying departments, while keeping the same overall character that reflects the identity of the whole campus.

The administration also needs to develop a strategy for outdoor soft-scape design, bringing trees around the building to increase the shaded areas without affecting the overall landscape design of the campus.

\section{Conclusion}

This paper was intended to examine the post-occupancy of the Faculty of Engineering (MSA University). It focused on the indoor environment and was meant to measure the performance of the building and the level of satisfaction of its occupants, and to what extent it succeeded in fulfilling their needs. Hence, the study could stand on good and problematic areas, and thus recommend ways for improvement and propose a foundation for design guidelines in similar future projects. To achieve this, a three-phase methodology was utilized, starting with the exploratory mechanisms (observations, interviews, precedent studies, and literature), followed by focused mechanisms (questionnaire, measurements, inventories and archives), and culminated with verification ones (walkthrough). In general, the study tackled three main areas: functionality, building quality and the impact of the building on both the exterior and the interior contexts.

It is the study's finding that in spite of the good intentions of the architectural design of the building, it did not meet the users' expectations in all occasions, as the results exposed positive aspects along with some problems that affected the performance of the building. Functionally, it has been realized that facilities are available on campus, but some of them are not sufficient with respect to the growing number of students and their consequent needs. A few facilities are not there and need to be considered (e.g., printing and copying centre). It was also found that, to a reasonable extent, the building quality was satisfactory for all user groups despite problems relating to thermal aspects, shading devices and energy consumption. As for the impact of the building, the study indicates several problematic areas including way finding, privacy and territoriality of both staff and students, as well as the identity of the building. Then, the study forwarded a batch of recommended actions to mitigate the effect of such shortcomings.

Finally, it is highly hoped that the administration would make good use of the study's findings and recommendations, which are intended to satisfy the needs of the building's users, improve the indoor environment, increase the sense of belonging to the college, and ultimately enhance the educational process. In addition, the university administration could utilize these findings to other buildings - whether existing, under construction, or proposed. Furthermore, these could also be employed by other universities in Egypt which 
Sameh M. T. El-Feki, Mohamed S. Saleh, Post-occupancy evaluation study of a university.......

may be facing similar conditions, as well as practitioners who are engaged in the construction of higher education buildings.

\section{REFERENCES}

[1] MSA (2014a) 'October University for Modern Sciences and Arts', Faculty of Engineering official records, the research team was granted an access to some of the faculty's official records.

[2] Watson, C. (2003). Review of building quality using post occupancy evaluation. Journal of Programme Education Building, Vol. 35: pp 1 - 5.

[3] Zimring, C. and Reizenstein, J. E. (1980). Post-Occupancy Evaluation: An Overview in Environment and Behavior. Vol 12: pp 429-451.

[4] Vischer, J. (2002). Post Occupancy Evaluation: A Multifaced Tool for Building Improvement. Federal Facilities Council. US: The National Academy Press. Chapter 3, pp. 23-34.

[5] Bruhns, H. and Isaacs, N. (1996). Building Quality Assessment. In Building Evaluation Techniques, edited by G. Baird, J. Gray, N. Isaacs, D. Kernohan, and G. McIndoe, pp. 53 - 58. McGraw-Hill.

[6] Preiser, W. F. E. and Vischer, J. C. (eds.) (2004). Assessing Building Performance: Methods and Case Studies. Oxford, UK: Elsevier.

[7] Lawrence, A.M., (2013). Post Occupancy Evaluation of on-Campus Students Hall of Residence: A Case Study of Obafemi Awolowo Hall of Residence Ile-Ife. Greener Journal of Science, Engineering and Technology Research, Vol. 3(1), pp. 001-011.

[8] Preiser, W. F.E., Rabinowitz, H. Z. and White, E. T. (1988). Post Occupancy Evaluation, Van Nostrand Reinhold, New York, NY.

[9] MSA (2014b) 'October University for Modern Sciences and Arts', official website, available at: http://msa.edu.eg/msauniversity/

[10] Zimring, C., Rashid, M. and Kampschroer, K. (2000). Facility Performance Evaluation. In Lawrence Federal Green Construction Guide for Specifies. US: General Services Administration.

[11] Gray, J. and Baird, G. (1996). How to Plan and Conduct Evaluations. In Building Evaluation Techniques, edited by G. Baird, J. Gray, N. Isaacs, D. Kernohan, and G. McIndoe, pp. 3 - 14. McGraw-Hill.

[12] Bonde, M. and Ramirez, J., (2015). A Post-Occupancy Evaluation Of A Green Rated And Conventional on-campus residence hall. International Journal of Sustainable Built Environment, Vol. 4, pp. 400-408.

[13] Ouf, M. M., Issa, M. H., Polyzois, P. and Phil Merkel, P. (2015). A Methodology To Evaluate The Effects Of School Buildings' Occupancy And Usage On Their Energy Consumption.

5th International/1 1 th Construction Specialty Conference, Vancouver, British Columbia, pp. 185-1:185-9.

[14] Mahgoub, Y. (1998) Post Occupancy Evaluation of Elementary School Buildings in Al Ain City, United Arab Emirates. Emirates Journal for Engineering Research, Volume 3 Number 1, pp. 1-12.

[15] Gabr, H. and Al-Sallal, K. (2002). Post Occupancy Evaluation of University Educational Buildings, In G. Moser et al. (ed.), People, Places, and Sustainability, Hogrefe \& Huber Publishers. pp. 229-241.

[16] Salama, A. (2008) When Good Design Intentions Do Not Meet Users' Expectations: Exploring Qatar University Campus Outdoor Spaces. International Journal of Architectural Research, Archnet-IJAR, Volume 2 - Issue 2, pp. 57-77.

[17] Zeisel, J. (1984). Inquiry by Design: Tools for Environment-Behavior Research. Cambridge: Cambridge University Press.

[18] Commission for Architecture and the Built Environment (2006). Assessing secondary school design quality, Research Report. UK: CABE, from:

http://webarchive.nationalarchives.gov.uk/20110118095356/http:/www.cabe.org.uk/files/assessi ng-secondary-school-design-quality.pdf

[19] Köppen-Geiger (2010). Köppen-Geiger climate classification website, from,

http://koeppen-geiger.vu-wien.ac.at/

[20] Jamaludin, A., Hussein, H. and Tahir, K. (2016). Resident's acceptance of internal courtyard buildings. MATEC Web of Conferences 66, 00098, IBCC 2016. 
دراسة تقييم ما بعد الإشغال لأحد المبانى الجامعية بالقاهرة

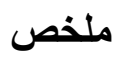

تقدم هذه الدر اسة تقييم ما بعد الإشغال من وجهة نظر المستخدمين لأداء أحد المباني داخل الحرم الجامعي

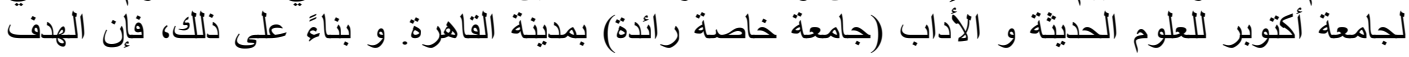

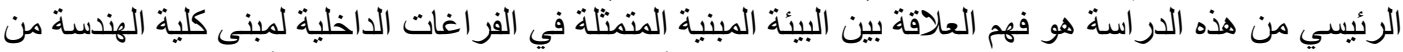

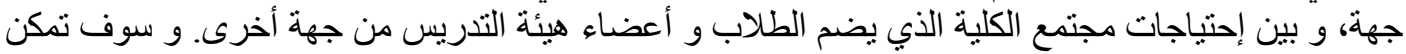

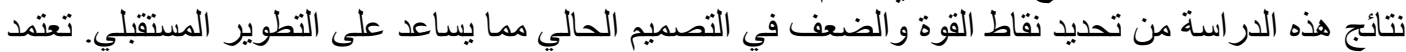

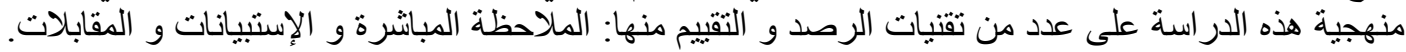

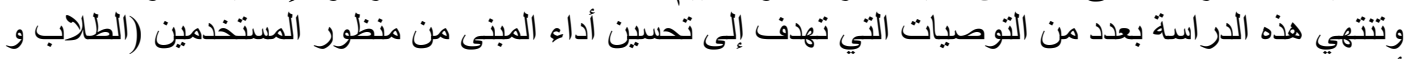

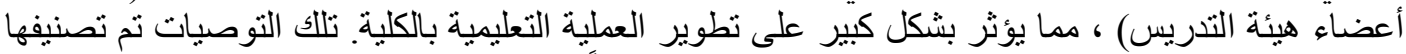

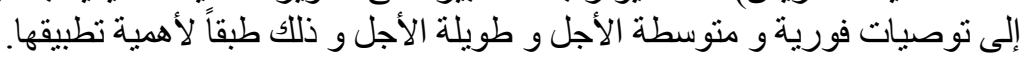

